\title{
Distributed manufacturing with 3-D printing: a case study of recreational vehicle solar photovoltaic mounting systems
}

\author{
Ben Wittbrodt ${ }^{1}$, John Laureto ${ }^{1}$, Brennan Tymrak ${ }^{2}$ and Joshua M Pearce ${ }^{1,3^{*}}$
}

\begin{abstract}
For the first time, low-cost open-source 3-D printing provides the potential for distributed manufacturing at the household scale of customized, high-value, and complex products. To explore the potential of this type of ultra-distributed manufacturing, which has been shown to reduce environmental impact compared to conventional manufacturing, this paper presents a case study of a 3-D printable parametric design for recreational vehicle (RV) solar photovoltaic (PV) racking systems. The design is a four-corner mounting device with the ability to customize the tilt angle and height of the standoff. This enables performance optimization of the PV system for a given latitude, which is variable as RVs are geographically mobile. The open-source 3-D printable designs are fabricated and analyzed for print time, print electricity consumption, mechanical properties, and economic costs. The preliminary results show distributed manufacturing of the case study product results in an order of magnitude reduction in economic cost for equivalent products. In addition, these cost savings are maintained while improving the functionality of the racking system. The additional electrical output for a case study RV PV system with improved tilt angle functionality in three representative locations in the U.S. was found to be on average over $20 \%$ higher than that for conventional mass-manufactured racking systems. The preliminary results make it clear that distributed manufacturing - even at the household level - with open-source 3-D printers is technically viable and economically beneficial. Further research is needed to expand the results of this preliminary study to other types of products.
\end{abstract}

Keywords: 3-D printing; Photovoltaic; Racking; Distributed manufacturing; Frugal innovation; Open-source; Household manufacturing; Transportation energy; Additive manufacturing

\section{Background}

It has been well established that the embodied energy of transportation for a wide range of products can have an appreciable percentage of the environmental impact of a product over its life cycle (Zhu and Sarkis 2006; Pearce et al. 2007; Cholette and Venkat 2009; Meisterling et al. 2009; Winnebeck 2011). Life cycle analysis indicates that ultra-distributed manufacturing with 3-D printers by prosumers (producer/consumers) would be beneficial from an environmental impact viewpoint (Kreiger and Pearce 2013a, b). This is the case if conventional manufacturing of equivalent

\footnotetext{
* Correspondence: pearce@mtu.edu

${ }^{1}$ Material Science and Engineering, Michigan Technological University, 1400

Townsend Dr., Houghton, Ml 49931, USA

${ }^{3}$ Electrical \& Computer Engineering, Michigan Technological University, 1400

Townsend Dr., Houghton, MI 49931, USA

Full list of author information is available at the end of the article
}

products is avoided by printing them. These savings are in part due to reductions in transportation embodied energy (Kreiger and Pearce 2013a, b). Recent developments in 3-D printing (an additive manufacturing technique, which intrinsically reduces material waste) have made distributed manufacturing of high-value products for household use both technically and economically viable, enabling individuals to fabricate an exponentially growing list of products to meet their own needs (Pearce et al. 2010; Wittbrodt et al. 2013). Sales figures indicate that personalized or desktop manufacturing with 3-D printers is a growing trend (Blua 2013; Economist 2012; Make 2013; Wohlers 2013). A wide range of products can now be produced by low-cost 3-D printers (Pearce et al. 2010; Martens et al. 2011; Wittbrodt et al. 2013), and open-source self-replicating rapid prototypers (or RepRaps) enable particularly fast 
scaling. RepRaps can manufacture over $50 \%$ of their own components (excluding fasteners) creating a low-cost and easily repairable $3-\mathrm{D}$ printer that can be used for both upgrades and fabricating replacement parts for low costs (Jones et al. 2011). To create the desired part, RepRaps sequentially deposit 100- to 400-micron layers of polylactic acid (PLA), acrylonitrile butadiene styrene (ABS), highdensity polyethylene (HDPE), and a wide range of other feedstock materials (Baechler et al. 2013; Kreiger et al. 2014; Mireles et al. 2013). Open-source 3-D printers have already demonstrated usefulness for developing engineering prototypes (Sells et al. 2010), customizing scientific equipment (Pearce 2012; Pearce 2014; Zhang et al. 2013), creating electronic sensors (Leigh et al. 2012; Anzalone et al. 2013), education (Gonzalez-Gomez et al. 2012; Zhang et al. 2013), co-creative product realization (Redlich et al. 2008), personal manufacturing (Devor et al. 2012), wire embedding (Bayless et al. 2010), modular robotics (Moses et al. 2009), tissue engineering (Miller et al. 2012), and appropriate technology for sustainable development (Pearce et al. 2010). This paper investigates the ability of the RepRap to be used in manufacturing directly following the open-source paradigm and uses a case study of a solar photovoltaic (PV) racking technology.

Recently, open-source principles have also been applied to solar PV technological development with promising results (Buitenhuis and Pearce 2012), and there is a growing interest in using 3-D printers to fabricate components of all kinds. There have also been a growing number designs of PV systems on Thingiverse, an online repository for 3-D printing designs (Makerbot Thingiverse 2012a, b, 2013a, b). The PV industry is currently undergoing significant structural adjustment as the costs of PV modules per watt has dropped $80 \%$ in the last 5 years, which has resulted in i) a marked decrease in the levelized cost of solar electricity (Branker et al. 2011) driving up demand and ii) the economic role of racking has been gaining prominence relative to the modules (Barbose et al. 2012). One area where 3-D printing can be used with PV is in custom module mounting.

Recreational vehicle (RV) applications of PV are unique in that the load is geographically mobile as is the structure where the PV is attached, and thus, there would be a benefit to customizing the bracket for each location to achieve an optimal tilt angle (Lewis 1987; Shu et al. 2006; Calabrò 2009; Mehleri et al. 2010). PV is already an attractive electricity generation option for RV users because it is often off grid and yet requires electrical power and there are several RV PV mounting systems on the market. Unfortunately, these mounting systems are often prohibitively expensive. For example, current RV-mounted solar PV modules use aluminum brackets attached to aluminum standoffs, which significantly hamper distribution as they have approximately the same cost per watt as the modules themselves
(Renvu 2014). As PV mounting and racking now makes up a significant fraction of PV system costs, the new developments in 3-D printing provide the potential for individuals to fabricate PV racking to drive down overall PV system prices. The primary requirement for a successful frugal RV PV mounting system is that it is mechanically stable to enable the RV to drive from location to location with the PV mounted on the top of the RV, and the secondary requirement is the ability for custom tilt angle adjustment for different latitudes.

In this paper, distributed manufacturing is the frugal innovation for this case study of RV PV racking system production with RepRaps. Parametric designs for a novel RV mounting system consisting of brackets and standoffs are developed. The design is a four-corner mounting device with the ability to customize the tilt angle and height of the standoff, which enables performance optimization for a given latitude. The open-source 3-D printable designs are fabricated and analyzed for print time, print electricity consumption, and mechanical properties. The additional electrical output for a case study RV PV system in three representative locations in the U.S. is simulated. These preliminary results are discussed, and conclusions are drawn about the technical and economic viability of this distributed approach to manufacturing.

\section{Methods}

RV conventional aluminum brackets for mounting RV PV modules are widely available in a Z-shape geometry composed of two horizontal mounting feet connected via a vertical riser. One of the feet is attached to the module, while the other is connected to a standoff mount. The load transferred to the mount from the module acts in such a way that a moment occurs in the bracket causing stresses to be present from bending. To serve as a functional replacement, a printed mount must be able to withstand the same moment as the aluminum mount. Therefore, a baseline maximum moment $(M)$ the aluminum bracket can support before failure was calculated for the aluminum bracket as well as stiffness to serve as design parameters for the printed mount using:

$$
M=\sigma_{\mathrm{y}} I / y
$$

where $\sigma_{\mathrm{y}}$ is the yield strength of the material, $I$ is the second moment of inertia, and $y$ is the distance from the neutral axis. For 6061-O aluminum, the yield strength was taken as 55.2 MPa (ASM 2013). Brinell Hardness was tested on the brackets, confirming the 6061-O alloy, with $29.9 \mathrm{MPa}$ experimentally tested and $30 \mathrm{MPa}$ being handbook comparison (ASM 2013). The dimensions of aluminum brackets are $1.8 \mathrm{~mm}$ thick and $38 \mathrm{~mm}( \pm 0.005 \mathrm{~mm})$ wide resulting in an area moment of $1.847 \times 10^{-11} \mathrm{~m}^{4}$ and a distance of $0.9 \mathrm{~mm}$ from the neutral axis to the surface where stresses 
are highest. The calculated maximum supported moment is $1.13 \mathrm{Nm}$, which translates to a force of $83.4 \mathrm{~N}$ (18.75 lbs) acting at the centroid of the mounting foot.

The basic bending stiffness of the aluminum bracket was determined by:

$$
K=E I
$$

where $E$ is Young's modulus. For the bracket with a Young's modulus of $68.9 \mathrm{GPa}$, the bending stiffness is $1.272 \mathrm{Nm}^{2}$.

ABS was chosen as the printing material due to its resistance to UV radiation and environmental conditions of wind, rain, and snow that it could experience while in use (Davis et al. 2004). ABS printed parts can be treated with acetone to smooth out and better seal the exterior of the parts, which see the most wear in use (Davis et al. 2004). To compare the aluminum parts to the 3-D ABS printed parts, ten ASTM Type I tensile test specimens were printed at $100 \%$ infill and tested in accordance with the ASTM D638 standard for testing plastics (ASTM 2013). These tests resulted in preliminary values of $27 \mathrm{MPa}$ for the tensile strength and $1.8 \mathrm{GPa}$ for $E$ (Tymrak et al. 2014). In order to compensate for the decrease in strength and modulus of the printed parts, the thickness was increased to $4 \mathrm{~mm}$ and the width held constant resulting in a maximum supportable moment of $2.74 \mathrm{Nm}$ or a $201.9 \mathrm{~N}$ (45.4 lbs) force and a stiffness in bending of $0.365 \mathrm{Nm}^{2}$. While the printed part can theoretically support a greater force than the aluminum bracket, it will deflect more due to having a lower stiffness in the loading configuration.

Due to the discrete nature of layer deposition in 3-D printing, the lamination strength of the layers in the direction of the part build is much lower than the tensile strength in the plane of deposition. However, this is only an issue when the print is loaded parallel to the $Z$ axis of the print and can be mitigated by loading parts perpendicular to the $Z$ axis of the print, such as how the mounting bracket is designed.

The 3-D printed parts were designed using OpenSCAD (Kintel and Wolf 2013), an open-source, script-based, parametric 3-D modeling program. Along with increasing the thickness, the geometry of the original part was modified to ensure that it would behave similarly to the aluminum part despite differences in material properties. A chamfer was added at the junction of the mounting bracket foot and the vertical riser to add extra support, increasing stiffness. This serves to fortify critical sections of the part where stress concentrations would be highest.

Finally, the 3-D printable racking component cost $\left(C_{\mathrm{T}}\right)$ was calculated by:

$$
C_{\mathrm{T}}=\Sigma t e+m p+v
$$

where $t$ is the printing time, $e$ is the electricity cost [\$/h] made up of the power consumed times the electric rate of $\$ 0.12 / \mathrm{kWh}$ (U.S. EIA 2013), $m$ is the mass [kg], $p$ is the polymer cost of $\$ 35 / \mathrm{kg}$ (note: ABS and PLA, the two most common polymers both sell for approximately the same cost), and $v$ is the cost of M8 threaded rod and two M8 nuts, which are required for each standoff and mounting bracket pair. The electricity use was measured to print the brackets with a multimeter $( \pm 0.005 \mathrm{kWh})$, and the finished printed components were weighed $( \pm 0.05 \mathrm{~g})$ with a digital balance. Bolt hardware was priced at McMaster-Carr (Elmhurst, IL, USA).

The parts were printed using a modified Prusa Mendel variety of RepRap 3-D printer, with maximum build dimensions of $200 \mathrm{~mm}^{2}$ in the $X$ and $Y$ directions and a $180-\mathrm{mm}$ height limit. For current bill of materials, building, and operating instructions, see http://www.appropedia.org/ MOST_HS_RepRap_build. The RepRap 3-D printer is able to print every part needed for the mounting system, aside from metal fasteners, with multiple parts fitting on the build platform to decrease print times. A layer resolution of $0.25 \mathrm{~mm}$ and a positioning accuracy of $0.1 \mathrm{~mm}$ resulted in uniformity throughout the part and an esthetic appeal that is lacking in the aluminum parts.

The yearly energy output and optimal tilt angles were calculated using PV Syst 6.0.6. Energy output was found from simulations for four 200-W RV-mounted PV modules using standard $\mathrm{Al}$ mounting and 3-D printed optimal tilt mounting for three representative locations (Minneapolis, MN, Boulder, CO, and Phoenix, AZ).

\section{Results and discussion}

Figure 1A, B shows the final design of the module mount in both the computer model of the $\mathrm{z}$ bracket and the standoff, respectively. Figure $1 \mathrm{C}$ compares the aluminum $\mathrm{z}$ bracket to the reinforced printed $\mathrm{z}$ bracket in black, Figure 1D shows the printed standoff before assembly and Figure 2 shows the 3-D printed and assembled bracket and standoff.

In addition to design changes to increase mechanical performance, the designs of the parts were made customizable to fit any particular application that may be useful to the end user. Tilt angle, mounting hardware type, height of standoff, and the base diameter can all be customized and tailored for a specific application using OpenSCAD to optimize the PV system as shown in Figure 3.

Another advantage of the 3-D printable design is the ability to easily modify the design for mechanical performance improvement, such as changing the size of a chamfer to give the end user optimized performance of the part depending on the type of conditions expected while driving and stationary. For example, those traveling through areas with known high-velocity winds may increase the cross section of components to provide additional mechanical strength.

Traditional aluminum standoffs and mounts cost $\$ 14.00$ for a set of four mounting brackets and $\$ 15.00$ per 

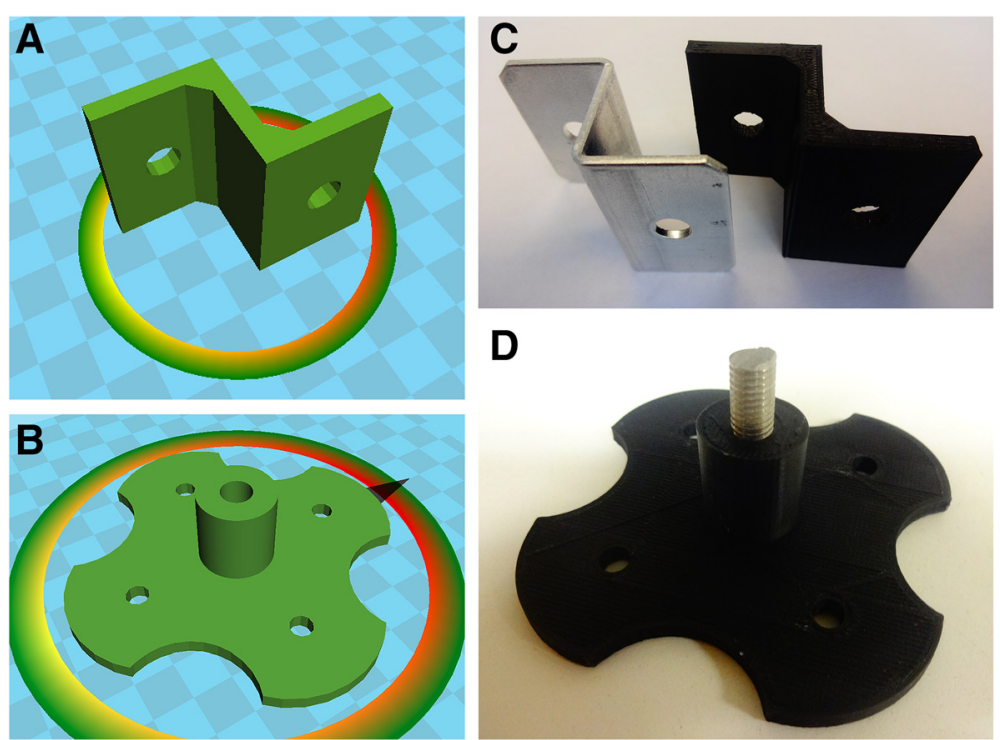

Figure 1 Final design of the module mount and comparison of aluminum z bracket and printed z bracket. (A) OpenSCAD design of z-mounting bracket, (B) OpenSCAD design of standoff, and (C) conventional aluminum z-mounting bracket and 3-D printed z-mounting bracket (in black). (D) Printed standoff partially assembled.

standoff and fasteners totaling $\$ 75.23(37.6$ cents $/ W)+$ shipping (Northern Arizona Wind \& Sun 2014). This currently is about half the cost of the PV on a per watt basis. The cost of the 3-D printable RV racking is $\$ 7.21 /$ module (3.6 cents $/ W$ ) when considering the printed parts' plastic and embodied energy (electricity) and fasteners for four mounting brackets and standoffs. There is thus a factor of 10 savings for the 3-D printable RV mounts, which also offer superior performance from the array because of the ability to tilt the modules closer

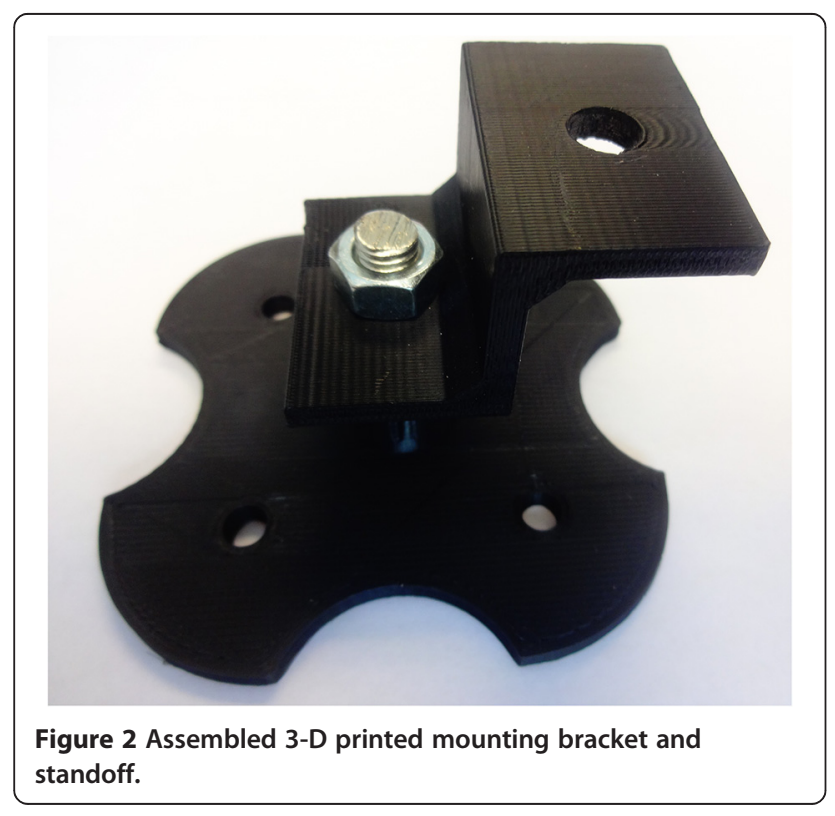

to their optimal tilt angle. As the size of the PV system gets smaller, the relative cost of the racking increases, so decreasing the cost of the racking can make smaller PV systems easier to afford for people looking to use them in apartments, or cottages that have lower electricity requirements compared to a typical household. It should be pointed out here that the RV PV system mounting is but a single example. Using the designs freely released for this project, many variations are possible for other applications. For example, flat roof and even tilted roof

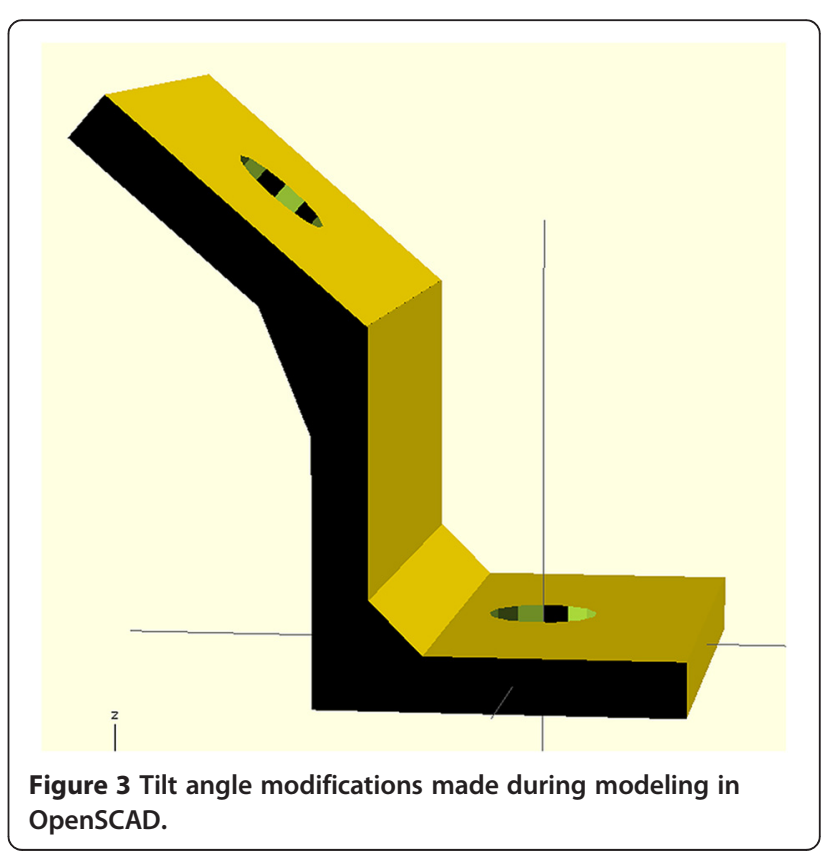


applications of PV that allow roof penetrations could use the existing design. However, with small alterations to the design PV racking could be customized for railings on apartments, facades, fences, carport awnings, etc. Similar results can expected for these other applications using a distributed manufacturing methodolgy.

These traditional mounts are also expected to last the life of the module without any required maintenance. More work is needed to determine if the polymer racking would have the same longevity. A continuation of this research could consist of adding carbon black to increase the reinforcement ability of the 3-D printed parts and aid in UV resistance (Clabbum et al. 1973).

With the ability to change the design of the mount in the modeling software come changes in cost. When the tilt angle is changed, the height of the mount must also change, which requires more materials and more costs, but with increased benefit in module performance. Operating the module at the optimal tilt angle increases the efficiency, which for three different locations was found to be an average increase over the three representative U.S. locations of over $20 \%$ as shown in Table 1 . The added total cost of the extended standoffs is $\$ 12.46$ per meter above the mounting bracket in order to operate the module at the optimal tilt angle. This increase in cost only applies to two of the four standoffs and can be minimized by tilting in landscape orientation.

It should be noted here that the costs of the RepRap 3-D printer itself and the human costs to operate the printer were not included in this study. In traditional manufacturing, the cost of the manufacturing equipment can be a substantial percentage of the cost of the resultant products; in this case, it was assumed that the value of the printer had already been realized in printing other products. This assumption is supported by a recent study that showed the cost of a RepRap 3-D printer could be easily recouped in under 1 year assuming only 20 common household items were printed (Wittbrodt et al. 2013). These household items could be printed in a weekend making the fractional cost of the capital equipment irrelevant to any economic study like this one that assumed the consumer already owned a 3-D printer.

The labor costs are slightly more complicated. It was assumed that the RV owners would do the printing themselves and not hire out the task. As the designs for the RV PV system have already been designed and open-sourced as part of this publication, the labor involved in manufacturing the products with an existing 3-D printer is trivial. The RV owner would either download the STL files, which were open-sourced as part of this study (or customize their brackets with the open-sourced SCAD files), and then slice and print on their RepRap. This process is only slightly more complicated than downloading and printing a pdf file on a color 2D printer. Much like conventional printers, tuned 3-D printers do not need to be watched as the print so the RV owner could spend their time any way they chose during the majority of the printing time. This makes the additional opportunity cost for prosumer manufacturing of the RV PV bracket system rather small (if it exists at all) as it would need to be compared to the cost (and time value lost) or either shopping in a retail store (and transportation time to and from the store) for a product or ordering it online and waiting for it to be delivered. In either case, the convenience and the ability to customize would provide even more savings than have been conservatively estimated here. The values of labor, however, were not quantified here as there is a high degree of variability in opportunity costs among consumers depending on their income, employment, and geographic location.

Providing open-source designs will allow 3-D printer owners and companies everywhere to begin distributed manufacturing of custom RV PV mounts allowing distribution to take place simultaneously throughout the country and driving competition between manufacturers ultimately benefiting the customers with the lowest prices possible. According to the Recreation Vehicle Industry Association, $21 \%$ of all U.S. households stated intentions to purchase an RV at some point in the future (RVIA 2013). There are approximately 115 million households in the U.S., equating to the potential for about 24 million RVs to be modified with the design. If each RV owner installed four 200-W modules, the total power would be over $19 \mathrm{GW}$, which is over six times the total U.S. installations in 2012. Distributed manufacturing PV racking creates a more customized product and drops costs by an order of magnitude, which has the potential to significantly expand the PV market not only in the U.S. but - as it pushes the costs down considerably - in the entire world.

Table 1 Electrical generation analysis of four 200-W PV modules over 1 year

\begin{tabular}{|c|c|c|c|c|c|}
\hline & \multirow{2}{*}{$\begin{array}{l}\text { Optimal tilt } \\
\text { angle }\left(^{\circ}\right)\end{array}$} & \multicolumn{2}{|c|}{ Module tilt } & \multicolumn{2}{|c|}{ Change in efficiency from flat orientation } \\
\hline & & Flat (kWh/year) & Optimal (kWh/year) & Increase (kWh/year) & Percent increase \\
\hline Minneapolis, MN & 41 & 238 & 297 & 59 & 25 \\
\hline Boulder, CO & 38 & 280 & 345 & 65 & 23 \\
\hline Phoenix, AZ & 32 & 349 & 404 & 55 & 16 \\
\hline Average & & & & 60 & 21 \\
\hline
\end{tabular}


In this case study, the product is environmentally friendly because of the intrinsic sustainability of PV systems (Pearce 2002). However, the use of the ultradistributed (or prosumer) manufacturing for the product will result in additional PV energy conversion improving the environmental performance of the product further (particularly if the RepRap is solar powered (King et al., 2014)). In this specific case, high-embodied-energy aluminum is replaced with low-embodied-energy plastic (or even recycled plastic) even further improving the environmental performance of the RV PV racking. However, material substitution is not necessary to improve the environmental performance of 3-D printed products. Preliminary life cycle analysis for manufacturing with RepRaps identical to those used in this study for more common household items indicates that distributed manufacturing has a smaller environmental impact than conventional manufacturing (Kreiger and Pearce 2013a, b). These environmental benefits are significantly enhanced when recycled polymers are used and even more so when using distributed recycling with RecycleBots (Baechler et al. 2013; Kreiger et al. 2013, 2014). Waste plastic filament extruders are much less developed than RepRaps, but there are several companies commercializing extruders that can act as RecycleBots directly and on KickStarter as of this writing. Filament manufactured with a RecycleBot further improves the economics of distributed manufacturing as it can produce $1 \mathrm{~kg}$ of filament from about empty 20 milk jugs for under 10 cents instead of $\$ 30$ to $60 / \mathrm{kg}$ from centralized filament suppliers. The economics of using a distributed approach to recycling and manufacturing with open-source equipment seems clear and may be a key factor along with the ability for ultra-customization that drives the reduced environmental impact for 3-D printing at the prosumer level. If the proliferation of open-source designs continues exponential growth (Wittbrodt et al. 2013), the value of owning a personal 3-D printer increases and could become commonplace for manufacturing a wide range of products.

As it appears possible (and perhaps likely) that an ever-expanding list of products will be manufactured by prosumers using personal 3-D printers, future work is needed to quantify not only the environmental impact of both individual products but also the wider impacts of a distributed manufacturing ecosystem. Potential large socio-economic shifts, changes in employment, alterations to resource scarcities, and concomitant reduced conflicts due to reduced spending on centrally manufactured products could have both direct and indirect effects on the environment, which are in substantial need for further study. The environmental performance of personal 3-D printing should not only address the life cycle analysis (LCA) of polymer products and energy use as has been done in the past but can also include the expanding array of printed materials and specialty chemicals. Finally, such LCAs should include the impact of chemicals that are sometimes used in post-processing printed objects. For example, acetone can be used to smooth out the approximately 200-micron step heights used in today's 3-D printing. Acetone can be relatively safely used with good ventilation, but other chemicals (such as dichloromethane, used to treat the common printing material PLA) are substantially more dangerous. LCAs could help guide the burgeoning industry of ultra-distributed manufacturing with open-source 3-D printing towards the safest and most environmentally benign techniques and chemicals.

\section{Conclusions}

The preliminary results of this study show distributed manufacturing using 3-D printing of the case study product of RV PV racking results in an order of magnitude reduction in economic cost for a superior product. The additional electrical output for a case study RV PV system in three representative locations in the U.S. was found to be on average over $20 \%$ higher than that for conventional mass-manufactured racking systems. The preliminary results indicate that distributed manufacturing - even at the household level - with open-source 3-D printers is technically and economically viable. Further research is necessary to expand the results of this preliminary study to other types of products and to complete full life cycle analysis on them to quantify the environmental impacts.

\section{Competing interests}

The authors declare that they have no competing interests.

\section{Authors' contributions}

BW Designed alternative racking, conducted cost analysis. JL Supported fabrication, analyzed commercial material. BT Characterized printed material. JP Participated in design study, guided expiriments. All authors read and approved the final manuscript.

\section{Author details}

${ }^{1}$ Material Science and Engineering, Michigan Technological University, 1400 Townsend Dr., Houghton, MI 49931, USA. ${ }^{2}$ Mechanical Engineering and Engineering Mechanics, Michigan Technological University, 1400 Townsend Dr., Houghton, MI 49931, USA. ${ }^{3}$ Electrical \& Computer Engineering, Michigan Technological University, 1400 Townsend Dr., Houghton, MI 49931, USA.

Received: 9 September 2014 Accepted: 3 December 2014 Published online: 03 November 2015

\section{References}

Anzalone, GC, Glover, AG, \& Pearce, JM. (2013). Open-source colorimeter. Sensors, 13(4), 5338-5346.

ASM Aerospace Specification Metals Inc. (2013). Aluminum 6061-O. http://asm.matweb.com/search/SpecificMaterial.asp?bassnum=MA6061O. Accessed 15/03/13. ASTM International. (2013). ASTM Standard D638, 2013. Standard test method for tensile properties of plastics. West Conshohocken: ASTM International.

Baechler, C, DeVuono, M, \& Pearce, JM. (2013). Distributed recycling of waste polymer into RepRap feedstock. Rapid Protyping Journal, 19(2), 118-125. Barbose, G, Darghouth, N, Ryan Wiser, R (2012). Tracking the Sun V: an historical summary of the installed price of photovoltaics in the United States from 1998 to 2011. Lawrence Berkeley National Laboratory. http://emp.lbl.gov/ sites/all/files/LBNL-5919e.pdf. Accessed 15/03/13. 
Bayless, J, Chen, M, \& Dai, B. (2010). Wire embedding 3D printer. Vancouver: Engineering Physics, University of British Columbia.

Blua, A (2013). A new industrial revolution: the brave new world of 3D printing. Radio Free Europe Radio Library. http://www.rferl.org/content/printing-3dnew-industrial-revolution/24949765.html. Accessed 30/04/13.

Branker, K, Pathak, MJM, \& Pearce, JM. (2011). A review of solar photovoltaic levelized cost of electricity. Renewable \& Sustainable Energy Reviews, 15, 4470-4482.

Buitenhuis, AJ, \& Pearce, JM. (2012). Open-source development of solar photovoltaic technology. Energy for Sustainable Development, 16, 379-388.

Calabrò, E. (2009). Determining optimum tilt angles of photovoltaic panels at typical north-tropical latitudes. Journal of Renewable and Sustainable Energy, 1(3), 033104

Cholette, S, \& Venkat, K. (2009). The energy and carbon intensity of wine distribution: a study of logistical options for delivering wine to consumers. Journal of Cleaner Production, 17, 1401-1413.

Clabbum, RJT, Penneck, RJ, \& Swinmurn, CJ. (1973). The outdoor performance of plastic materials used as cable accessories. IEEE Transactions on Power Apparatus and Systems, PAS-92(6), 1833-1842.

Davis, P, Tiganis, BE, \& Burn, LS. (2004). The effect of photo-oxidative degradation on fracture in ABS pipe resins. Polymer Degradation and Stability, 84(2), 233-242.

DeVor, RE, Kapoor, SG, Cao, J, \& Ehmann, KF. (2012). Transforming the landscape of manufacturing: distributed manufacturing based on desktop manufacturing (DM)2. Journal Elec Packaging, 134(4), 61801

The Economist (2012). A third industrial revolution. April 21, 2012

U.S. Energy Information Administration (2013). Electric power monthly: average retail price of electricity to ultimate customers. http://www.eia.gov/electricity/ monthly/epm_table_grapher.cfm?t=epmt_5_3. Accessed 30/03/13.

Gonzalez-Gomez, J, Valero-Gomez, A, Prieto-Moreno, A, \& Abderrahim, M (2012). A new open source 3D-printable mobile robotic platform for education. In Ruckert, Ulrich, Joaquin, Sitte, and Felix, Werner (Eds.) Advances in autonomous mini robots (pp. 49-62). Berlin: Springer.

Jones, R, Haufe, P, Sells, E, Iravani, P, Olliver, V, Palmer, C, \& Bowyer, A. (2011). RepRap - the replicating rapid prototyper. Robotica, 29(1), 177-191.

King, DL, Babasola, A, Rozario, J, \& Pearce, JM. (2014). Mobile open-source solarpowered 3-D printers for distributed manufacturing in off-grid communities. Challenges in Sustainability, 2(1), 18-27.

Kintel, M, Clifford Wolf, C (2013). OpenSCAD - The Programmers Solid 3D CAD Modeller. http://www.openscad.org/. Accessed 05/02/13.

Kreiger, M, \& Pearce, JM (2013a). Environmental impacts of distributed manufacturing from 3-D printing of polymer components and products. MRS Online Proceedings Library, 1492, mrsf12-1492-g01-02

Kreiger, M, \& Pearce, JM. (2013b). Environmental life cycle analysis of distributed 3-D printing and conventional manufacturing of polymer products. ACS Sustainable Chemistry \& Engineering, Engineering, 1(12), 1511-1519.

Kreiger, M, Anzalone, GC, Mulder, ML, Glover A, \& Pearce, JM (2013). Distributed recycling of post-consumer plastic waste in rural areas. MRS Online Proceedings Library, 1492, mrsf12-1492-g04-06

Kreiger, MA, Mulder, ML, Glover, AG, \& Pearce, JM. (2014). Life cycle analysis of distributed recycling of post-consumer high density polyethylene for 3-D printing filament. Journal of Cleaner Production, 70, 90-96.

Leigh, SJ, Bradley, RJ, Purssell, CP, Billson, DR, \& Hutchins, DA. (2012). A simple, low-cost conductive composite material for 3D printing of electronic sensors. Plos One, 7(11), e49365.

Lewis, G. (1987). Optimum tilt of a solar collector. Solar \& Wind Technology, 4(3), 407-410.

Make (2013). Make: ultimate guide to 3D printing, O'Reilly, Winter 2013.

Makerbot Thingiverse (2012a). Solar Joos Bike Rack Mount. http:// www.thingiverse.com/thing:25260. Accessed 22/03/13.

Makerbot Thingiverse (2012b). Solar Powered Stereo http://www.thingiverse.com/ thing:38262. Accessed 22/03/13.

Makerbot Thingiverse (2013a). Dual Axis Solar Tracker http:// www.thingiverse.com/thing:53321. Accessed 22/03/13.

Makerbot Thingiverse (2013b). Solar panel terminal box. http:// www.thingiverse.com/thing:62068. Accessed 22/03/13.

Martens, T, Mears, L, Dotson, M, Graham, M, \& Sanger, P. (2011). Use of fused deposition modeling of polyphenylsulfone for centrifugal casting of polyurethane: material, surface, and process considerations. J. Manuf. Sci. E., 133(5), 051003
Mehleri, ED, Zervas, PL, Sarimveis, H, Palyvos, JA, \& Markatos, NC. (2010). Determination of the optimal tilt angle and orientation for solar photovoltaic arrays. Renewable Energy, 35(11), 2468-2475.

Meisterling, K, Samaras, C, \& Schweizer, V. (2009). Decisions to reduce greenhouse gases from agriculture and product transport: LCA case study of organic and conventional wheat. Journal of Cleaner Production, 17, 222-230.

Miller, JS, Stevens, KR, Yang, MT, Baker, BM, Nguyen, DHT, Cohen, DM, Esteban Toro, E, Chen, AA, Galie, PA, Yu, X, Chaturvedi, R, Bhatiaand, SN, \& Chen, CS. (2012). Rapid casting of patterned vascular networks for perfusable engineered three-dimensional tissues. Nature Materials, 11, 768-774.

Mireles, J, Kim, H, Lee, H, Espalin, D, Medina, F, MacDonald, E, \& Wicker, R. (2013). Development of a fused deposition modeling system for low melting temperature metal alloys. J. Electron. Packaging, 135(1), 011008.

Moses, M, Yamaguchi, H, \& Chirikjian, GS (2009). Towards cyclic fabrication systems for modular robotics and rapid manufacturing. In Proceedings of robotics: science and systems.

Northern Arizona Wind \& Sun (2014). Z-Bracket RV Mounting Feet (set of 4). http://www.solar-electric.com/sopozrvmofes.html. Accessed 03/04/14.

Pearce, J. (2002). Photovoltaics - a path to sustainable futures. Futures, $34(7), 663-674$.

Pearce, JM. (2012). Building research equipment with free, open-source hardware. Science, 337(6100), 1303-1304.

Pearce, JM (2014). Open-Source Lab: how to build your own hardware and reduce research costs. Elsevier, New York, NY.

Pearce, JM, Johnson, SJ, \& Grant, GB. (2007). 3D-mapping optimization of embodied energy of transportation. Resources, Conservation and Recycling, 51, 435-453.

Pearce, JM, Blair, CM, Laciak, KJ, Andrews, R, Nosrat, A, \& Zelenika-Zovko, I. (2010). 3-D printing of open source appropriate technologies for self-directed sustainable development. Journal of Sustainable Development, 3(4), 17-29.

Redlich, T, Wulfsberg, JP, \& Bruhns, FL (2008). Virtual factory for customized open production. 15th Int. Product Dev. Management Conf., Hamburg.

Renvu (2014). http://www.renvu.com/. (visited 12/10/2014).

RVIA (2013). New RVIA research shows record level of RV ownership. http://www.rvia.org/?ESID=trends. Accessed 15/04/13.

Sells, E, Smith, Z, Bailard, S, Bowyer, A, \& Olliver, V (2010). RepRap: the replicating rapid prototyper: maximizing customizability by breeding the means of production. In FT Piller and MM Tseng (Eds.), Handbook of research in mass customization and personalization: strategies and concepts (vol. 1). World Scientific, Hackensack, NJ.

Shu, N, Kameda, N, Kishida, Y, \& Sonoda, H. (2006). Experimental and theoretical study on the optimal tilt angle of photovoltaic panels. Journal of Asian Architecture and Building Engineering, 5(2), 399-405.

Tymrak, BM, Kreiger, M, \& Pearce, JM (2014). Mechanical properties of components fabricated with open-source 3-D printers under realistic environmental conditions. Materials \& Design, 58, 242-246.

Winnebeck, KH. (2011). An abbreviated alternatives assessment process for product designers: a children's furniture manufacturing case study. J Cleaner Production, 19, 464-476.

Wittbrodt, BT, Glover, AG, Laureto, J, Anzalone, GC, Oppliger, D, Irwin, JL, \& Pearce, JM. (2013). Life-cycle economic analysis of distributed manufacturing with open-source 3-D printers. Mechatronics, 23, 713-726.

Wohlers Associates. (2013). Additive manufacturing and 3D printing state of the industry annual worldwide progress report. Fort Collins: Wohlers Associates.

Zhang, C, Anzalone, NC, Faria, RP, \& Pearce, JM. (2013). Open-source 3D-printable optics equipment. PloS One, 8(3), e59840.

Zhu, Q, \& Sarkis, J. (2006). An inter-sectoral comparison of green supply chain management in China: drivers and practices. Journal of Cleaner Production, 14, 472-486. 